\title{
A particle counting immunoassay for the direct detection of Clostridium difficile serogroup specific antigen in faecal specimens
}

\author{
V. AVESANI, C. CAMBIASO, J. L. GUARIN, A. LICK and M. DELMÉE* \\ Microbiology Unit and Experimental Medicine Unit, Catholic University of Louvain, Faculty of Medicine, \\ B-1200 Brussels, Belgium
}

\begin{abstract}
Summary. The potential of a particle counting immunoassay (PACIA) for the direct detection of Clostridium difficile serogroup $\mathrm{G}$ specific antigen in faecal specimens was evaluated. $\mathrm{F}\left(\mathrm{ab}^{\prime}\right)_{2}$ fragments from a rabbit anti-serogroup $\mathrm{G}$ antiserum were covalently coupled to carboxylated latex beads. This reagent was mixed with acid extracts of faecal specimens and the reaction was assayed with an optical counter which discriminated unagglutinated from agglutinated latex particles. Culture for $C$. difficile, faecal cytotoxin detection, PACIA and serogrouping of $C$. difficile isolates were performed on 249 stools. Of the 71 culture-negative specimens, none gave a positive result in the cytotoxin assay or in PACIA. Faecal cytotoxin was detected in 100 of the 178 culture-positive specimens. PACIA was positive for 63 of the 71 faecal specimens that yielded serogroup $\mathrm{G} C$. difficile on culture. PACIA gave negative results for all other culture-positive stools tested with one exception, from which a serogroup A7 C. difficile strain was isolated. PACIA detection of serogroup $\mathrm{G}$ antigen in faecal specimens showed a sensitivity of $88.7 \%$, a specificity of $99.7 \%$, a predictive value of a positive culture with a serogroup $\mathrm{G}$ strain of $98.4 \%$, and a predictive value for specimens that were culture-negative for a serogroup G strain of $95.6 \%$. The results indicate that PACIA with specific antiserum is a rapid and reliable method for detecting serogroup specific antigens of $C$. difficile in faecal specimens. Clinical applications of the method are discussed.
\end{abstract}

\section{Introduction}

Serogrouping of Clostridium difficile by slide agglutination with rabbit antisera allows the differentiation of 10 serogroups. ${ }^{1}$ The epidemiology of $C$. difficile infection, particularly nosocomial transmission in hospital outbreaks, has been studied by this and other typing methods such as polyacrylamide gel electrophoresis (PAGE), immunoblotting, plasmid profiles or restriction endonuclease profiles. ${ }^{2-8}$ Several correlations between serogroup, toxigenicity and clinical course have been observed. Toxigenic isolates of serogroups $\mathrm{C}, \mathrm{H}$ and $\mathrm{K}$ are usually implicated in colitis in adults, but isolates of serogroups $\mathrm{B}, \mathrm{F}$ and $\mathrm{X}$ are isolated almost exclusively from asymptomatic children. ${ }^{1}$ Serogroup $F$ strains produce a cytotoxin but no toxin $\mathrm{A}$ and are unable to induce colitis in animal models, ${ }^{9}$ and strains of serogroups B, D and I are nontoxigenic. ${ }^{1}$

Correlations between serogroups and PAGE were also found. ${ }^{10}$ Specific profiles were associated with each of the 10 serogroups, except serogroup A, for which 12 different profiles were observed, designated

Received 1 June 1993; revised version accepted 6 Oct. 1993.

* Correspondence should be sent to Dr M. Delmée.
A1-A12. Later we showed that the cross-agglutination among serogroup A strains was due to a common flagellar antigen, and removal of the flagella allowed specific slide agglutination of the 12 PAGE subgroups of A with 12 corresponding antisera. ${ }^{11} \mathrm{~A}$ specific somatic antigenic determinant was identified for each serogroup and the corresponding protein band was located on PAGE profiles. ${ }^{12}$

Here, we describe the direct detection of serogroup $\mathrm{G}$ specific $C$. difficile antigen in faecal specimens by a particle counting immunoassay (PACIA). This method is a sensitive homogeneous non-isotopic latex agglutination assay in which the extent of the immune reaction is assayed by counting unagglutinated latex particles after the suspension of antibody-coated particles has been incubated with the antigen. ${ }^{13}$

\section{Materials and methods}

\section{Faecal specimens}

Stool samples from patients at the St-Luc University Hospital of Brussels suspected of having C. difficileassociated disease were submitted to the routine laboratory. Those examined in this study comprised: 
135 consecutive culture-positive stools; 71 randomly selected culture-negative stools; and 43 additional faecal specimens from which serogroup $\mathrm{G} C$. difficile strains had been isolated. All specimens were cultured on cycloserine cefoxitin fructose agar (CCFA) for C. difficile ${ }^{14}$ and assayed directly for cytotoxin on HeLa cells with specific neutralisation by $C$. sordellii antiserum ${ }^{1}$. When not processed immediately for antigen detection by PACIA, faeces were stored at $-80^{\circ} \mathrm{C}$. C. difficile isolates were identified as described previously. ${ }^{1}$ They were serotyped by slide agglutination, and serogroup A strains were further differentiated on the basis of PAGE profiles. ${ }^{1,10}$ Isolates of C. difficile were tested for cytotoxin production in the specific neutralisation HeLa cell assay, as for faeces, but with the filtrate of a 5-day culture in anaerobic liquid medium (LM) as described previously. ${ }^{1}$

\section{Antiserum preparation}

A rabbit antiserum against the serogroup specific antigenic determinant was prepared with ATCC 43599 , the serogroup $\mathrm{G}$ reference strain, as described previously. ${ }^{12}$ Briefly, cells from an 18 -h culture in LM were sonicated and centrifuged. Two volumes of the supernate were mixed with one volume of SDS buffer (25 mM Tris-hydrochloride with 2-mercaptoethanol $15 \% \mathrm{v} / \mathrm{v}$, glycerol $30 \% \mathrm{v} / \mathrm{v}$, sodium dodecyl sulphate $10 \% \mathrm{w} / \mathrm{v}$ and bromophenol blue $0 \cdot 1 \%$ ). After heating at $100^{\circ} \mathrm{C}$ for $5 \mathrm{~min}, 1400 \mu \mathrm{l}$ of the homogenate were loaded on to a $20 \mathrm{~cm} \times 25 \mathrm{~cm}$ polyacrylamide $10 \%$ gel in single $190-\mathrm{mm}$ wide wells, and electrophoresed at room temperature for $15 \mathrm{~h}$ at $60 \mathrm{~V}$. Low mol.-wt standards were from BioRad Laboratories. Gels were stained with Coomassie Blue. The band corresponding to the specific antigen was excised and electro-eluted in dialysis bags with Tris-glycine buffer, $\mathrm{pH} 8 \cdot 3$, containing SDS $0.01 \%$. After centrifugation, the liquid was dialysed against ammonium bicarbonate buffer $1 \%, \mathrm{pH} 7 \cdot 8$, and concentrated by lyophilisation. Antiserum was raised in rabbits by repeated intradermal injection with $2 \mathrm{ml}$ of a $1: 1$ emulsion of purified serogroup $\mathrm{G}$ protein solution $(0.5 \mathrm{mg} / \mathrm{ml})$ in incomplete Freund's adjuvant. The rabbits were given weekly injections for 6 weeks, then monthly for 2 months, and then bled.

\section{PACIA latex reagents}

Two reagents were prepared, one from the serum of rabbits immunised as described, and the other, control, from unimmunised animals. The IgG fraction was isolated by treatment with 6,9-diamino-acridine lactate (Rivanol $0.4 \%$ ), $\mathrm{pH} \mathrm{8.0,} \mathrm{followed} \mathrm{by} \mathrm{precipi-}$ tation with $4 \cdot 1 \mathrm{M}$ ammonium sulphate, $\mathrm{pH} 7 \cdot 5 . \mathrm{F}\left(\mathrm{ab}^{\prime}\right)_{2}$ fragments were prepared by peptic digestion of purified IgG in $0.1 \mathrm{M}$ acetate buffer, $\mathrm{pH} 4.5$, for $20 \mathrm{~h}$ at $37^{\circ} \mathrm{C}$ with an enzyme:protein ratio of $1: 50 \mathrm{w}: \mathrm{w}$. The reaction was stopped by increasing the $\mathrm{pH}$ to 7 with
$1 \mathrm{M}$ Tris. $\left.\mathrm{F}(\mathrm{ab})_{2}\right)_{2}$ fragments were purified by chromatography on Ultrogel AcA 4-4 and covalently coupled to carboxylated $0 \cdot 8-\mu \mathrm{m}$ diameter latex beads (Estafor K 150, Rhône-Poulenc, Courbevoie, France) by the carbodiimide method. ${ }^{15}$ The coated particles were stored at $-20^{\circ} \mathrm{C}$ in small volumes. Before use, the latex particles were diluted 200-fold with GBS $(0.1 \mathrm{~m}$ glycine, $0 \cdot 17 \mathrm{M} \mathrm{NaCl}, \mathrm{pH} 9 \cdot 2$ ) containing bovine serum albumin $10 \mathrm{~g} / \mathrm{L}$, and sodium azide $40 \mathrm{mg} / \mathrm{L}$, and sonicated for $10 \mathrm{~s}$.

\section{PACIA method}

One $\mathrm{ml}$ of faeces was homogenised with $2 \mathrm{ml}$ of saline. The suspension was adjusted to $\mathrm{pH} 2$ with $\mathrm{HCl}$, shaken at room temperature for $30 \mathrm{~min}$ and centrifuged at $5000 \mathrm{~g}$ for $30 \mathrm{~min}$. The supernate was adjusted to $\mathrm{pH} 7$ with 1 м Tris buffer. For cultures of $C$. difficile, $1 \mathrm{ml}$ of a 24-h culture on $\mathrm{LM}$ was used rather than $1 \mathrm{ml}$ of stool sample. Twenty-five $\mu \mathrm{l}$ of this acid extract was mixed with $25 \mu \mathrm{l}$ of the first additive ( $3 \mathrm{M} \mathrm{NaCl}$ with Dextran T 50020 g/L; Pharmacia, Uppsala, Sweden) and $25 \mu \mathrm{l}$ of the second additive (GBS with normal rabbit serum $100 \mathrm{ml} / \mathrm{L}$ and $\mathrm{F}\left(\mathrm{ab}^{\prime}\right)_{2}$ fragments of $\mathrm{IgG}$ from non-immunised rabbits $25 \mathrm{~g} / \mathrm{L}$ ) and incubated at $37^{\circ} \mathrm{C}$ for $40 \mathrm{~min}$. Twenty-five $\mu \mathrm{l}$ of antibody-coated latex suspension were added and the mixture was vortex mixed at $37^{\circ} \mathrm{C}$ for $40 \mathrm{~min}$ in a purpose-built incubator-agitator. After stopping the reaction by the addition of $0.75 \mathrm{ml}$ of GBS, unagglutinated particles were counted in an optical counter which discriminated the unagglutinated from the agglutinated latex particles. ${ }^{13}$ The concentration of antigen was inversely proportional to the number of unagglutinated particles.

\section{Results}

The PACIA was calibrated with 10 -fold dilutions of the supernate from a 2-day culture of ATCC 43599 in $\mathrm{LM}$ centrifuged at $5000 \mathrm{~g}$ for $30 \mathrm{~min}$ (figure). Uninoculated broth controls gave a peak count considered as $100 \%$, corresponding to the absence of specific agglutination. A peak count $<90 \%$ of the control was considered to be a positive result for serogroup $G$

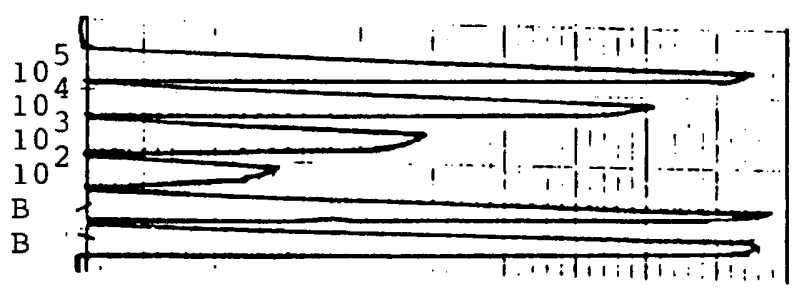

Figure. PACIA print-outs for samples of the supernate from a 2-day LM culture of the reference strain of serogroup G (ATCC 43599) diluted in the range $10^{2}-10^{5}$. Sample peaks designated $\mathrm{B}$ are noagglutination controls. Unagglutinated latex particles are counted in this assay, so a sample yielding counts $<90 \%$ of the noagglutination controls is considered to be a positive result. 
Table. Results of PACIA for the various serogroups isolated

\begin{tabular}{|c|c|c|c|c|}
\hline \multirow{2}{*}{ Serogroup } & \multicolumn{2}{|c|}{ Number of strains $(\%)$} & \multicolumn{2}{|c|}{ Number of faeces $(\%)$} \\
\hline & isolated & toxigenic & $\begin{array}{l}\text { cytotoxin } \\
\text { positive }\end{array}$ & $\begin{array}{l}\text { PACIA } \\
\text { positive }\end{array}$ \\
\hline G & 71 & $68(96)$ & $43(60)$ & $63(89)$ \\
\hline A & 20 & $16(80)$ & $14(70)$ & $1(5)$ \\
\hline $\mathrm{C}$ & 42 & $32(76)$ & $27(64)$ & 0 \\
\hline D & 4 & 0 & 0 & 0 \\
\hline $\mathrm{H}$ & 25 & $19(76)$ & $11(44)$ & 0 \\
\hline $\mathbf{F}$ & 1 & $1(100)$ & $1(100)$ & 0 \\
\hline K & 12 & $5(45)$ & $4(33)$ & 0 \\
\hline $\mathrm{X}$ & 3 & 0 & 0 & 0 \\
\hline Totals & 178 & $141(79)$ & $100(56)$ & $64(36)$ \\
\hline
\end{tabular}

antigen. Antigen was detectable in the culture supernate up to the $10^{4}$ dilution (figure).

Of the 71 culture-negative specimens, none gave a positive result in the cytotoxin assay or in PACIA. From the 178 culture-positive specimens, $C$. difficile strains were isolated,'serogrouped and investigated for cytotoxin production in vitro. All isolates were typable by slide agglutination, and were of serogroups $\mathrm{A}, \mathrm{C}$, $\mathrm{D}, \mathrm{F}, \mathrm{G}, \mathrm{H}, \mathrm{K}$ or X. PAGE subtypes of the 20 isolates of serogroup A were: nine in A1, three each in A10, A8 and $\mathrm{A} 5$; one in $\mathrm{A} 7$; and one with a previously undocumented PAGE profile.

Faecal cytotoxin was detected in 100 of the 178 culture-positive specimens, including 43 of the 71 stool samples that yielded serogroup $\mathrm{G}$ strains. Of the 178 isolates of $C$. difficile, 141 produced cytotoxin in vitro. The results obtained by PACIA are compared with isolate serogroup in the table. PACIA gave positive results in 63 of the 71 faecal specimens from which a strain of serogroup $\mathrm{G}$ was isolated. PACIA gave negative results for all other stool samples, with one exception, from which a strain of serogroup A7 was isolated. The performance of PACIA in the detection of serogroup $\mathrm{G}$ antigen in faecal specimens was: sensitivity, $88.7 \%$; specificity, $99.7 \%$; predictive value of a positive reaction, $98.4 \%$; predictive value of a negative reaction, $95 \cdot 6 \%$.

The eight serogroup $G$ isolates from faecal specimens that gave negative results by PACIA were grown in LM which was then tested by PACIA. All gave a positive result. By contrast, the serogroup A7 strain from the stool that was positive in PACIA gave a negative PACIA result.

\section{Discussion}

Detection of bacterial antigen in biological specimens has the obvious advantage of reducing the diagnostic delay, provided that it is specific and sensitive. An early latex agglutination assay for C. difficile toxin A in faece ${ }^{16,17}$ was later demonstrated to be specific not for the toxin but for an enzyme. The test is still used in some laboratories for screening. ${ }^{18,19}$ More recently, several commercial kits for the detec- tion of toxin $\mathrm{A}$ or for toxins $\mathrm{A}$ and $\mathrm{B}$ have yielded promising results. ${ }^{20-22}$ By contrast, our approach, having previously identified serogroup-specific antigens and established correlations between these serogroups and pathogenicity, has been to investigate methods that detect serogroup-specific antigens in stool samples.

PACIA is an immunological method which has been exploited in many diagnostic applications, ${ }^{13,15,23}$ and which can attain a sensitivity in the femtogram $/ \mathrm{ml}$ range. This study demonstrates that PACIA is able to detect serogroup G-specific antigen in faecal specimens with a sensitivity of $88.7 \%$ and a specificity of $99.4 \%$. We believe that the acid extraction of antigens from faeces described here may be, in part, responsible for the excellent results obtained. Other extraction procedures, such as simple sonication, yielded much less convincing results (unpublished data).

There were eight false negative and one false positive PACIA results in this series. The false negatives indicate a problem with assay sensitivity rather than specificity, as culture supernates from each of the eight isolates from these specimens gave positive PACIA results. The single false positive result was probably not due to antigenic cross-reaction with the serogroup A7 C. difficile isolate from this specimen, as PACIA results on culture supernates of this isolate were negative. This apparently anomalous positive reaction was more probably due to the additional presence of a serogroup $\mathrm{G}$ strain in such low relative numbers that it remained unrecognised as a distinct isolate. The concomitant presence of two distinct strains of C. difficile in the same specimen has been reported. ${ }^{24}$ Unfortunately we did not have the opportunity to reculture the stool to check this possibility.

The typing aspect of serogrouping, and the correlation between serogroup and virulence of $C$. difficile, ${ }^{9,25}$ make the PACIA approach well suited to clinical practice. Within a few hours, we were able to detect not only the presence of $C$. difficile in stools, but also to give an indication of the likely virulence of the organism and to specify a serogroup for epidemiological tracing. The main interest of rapid typing in routine practice is the ability to identify patients who have been colonised during hospital outbreaks. Nosocomial transmission of $C$. difficile has been well demonstrated. ${ }^{6}$ Severe outbreaks caused by a single epidemic strain have been reported, and some serogroups are thought to show particular predilection to cause outbreaks. ${ }^{2,4}$ Toxigenic strains of serogroup C, which are more resistant to antibiotics than other serogroups, are most often implicated in outbreaks. Conventional typing of isolates, by immunoblotting, PAGE profile or slide serogrouping, is much slower than the PACIA method described here. During an outbreak, the early PACIA detection of patients colonised with the epidemic strain could allow more effective preventive measures.

Equally, serogrouping results may be important in the detection of colonisation with strains that protect 
against symptomatic infection. The protective role of colonisation with non-toxigenic strains that prevent subsequent colonisation by toxigenic strains has been demonstrated in animal models. Borriello and Barclay showed that prior colonisation of hamsters with nonpathogenic strains protects the animals against ileocaecitis when challenged with a toxigenic strain. ${ }^{26}$ Similarly, Depitre et al. showed that mice colonised by a serogroup $F$ strain that produces a cytotoxin but no toxin A do not develop intestinal disease and are protected when challenged subsequently with a serogroup C strain which would otherwise kill the animals. ${ }^{9}$ In man, administration of a non-toxigenic isolate to patients suffering from $C$. difficile-associated colitis at the end of vancomycin therapy can prevent relapse. ${ }^{27}$ Some serogroups (B, D and I) do not produce either of the toxins implicated in disease, and another $(\mathrm{F})$ produces only the cytotoxin; isolates of these serogroups are not pathogenic. ${ }^{1,9}$ Rapid detection and serogrouping in patients colonised with these serogroups could contra-indicate antibiotic therapy.

\section{References}

1. Delmée M, Homel M, Wauters G. Serogrouping of Clostridium difficile strains by slide agglutination. $J$ Clin Microbiol 1985; 21 : 323-327.

2. Tabaqchali S, Holland D, O'Farrell S, Silman R. Typing scheme for Clostridium difficile: its application in clinical and epidemiological studies. Lancet 1984; 1 : 935-938.

3. Heard SR, O'Farrell S, Holland D, Crook S, Barnett MJ, Tabaqchali S. The epidemiology of Clostridium difficile with use of a typing scheme: nosocomial aquisition and cross-infection among immunocompromised patients. $J$ Infect Dis 1986; 153: 159-162.

4. Delmée M, Bulliard G, Simon G. Application of a serogrouping technique for Clostridium difficile in an outbreak of antibiotic associated diarrhoea. $J$ Infect 1986; 13: 5-10.

5. Kuijper EJ, Oudbier JH, Stuifbergen WN, Jansz A, Zanen HC. Application of whole-cell DNA restriction endonuclease profiles to the epidemiology of Clostridium difficile-induced diarrhea. J Clin Microbiol 1987; 25: 751-753.

6. McFarland LV, Mulligan ME, Kwok RYY, Stamm WE. Nosocomial acquisition of Clostridium difficile infection. $N$ Engl J Med 1989; 320: 204-210.

7. Clabots CR, Peterson LR, Gerding DN. Characterization of a nosocomial Clostridium difficile outbreak by using plasmid profile typing and clindamycin susceptibility testing. $J$ Infect Dis 1988; 158: 731-736.

8. Barbut F, Depitre C, Delmée M, Corthier G, Petit J-C. Comparison of enterotoxin production, cytotoxin production, serogrouping, and antimicrobial susceptibilities of Clostridium difficile strains isolated from AIDS and human immunodeficiency virus-negative patients. J Clin Microbiol 1993; 31 : 740-742.

9. Depitre C, Delmée M, Avesani V et al. Serogroup F strains of Clostridium difficile produce toxin B but no toxin A. J Med Microbiol 1993; 38: $434-441$.

10. Delmée M, Laroche Y, Avesani V, Cornelis G. Comparison of serogrouping and polyacrylamide gel electrophoresis for typing Clostridium difficile. J Clin Microbiol 1986; 24: 991-994.

11. Delmée M, Avesani V, Delferriere N, Burtonboy G. Characterization of flagella of Clostridium difficile and their role in serogrouping reactions. J Clin Microbiol 1990; 28: 2210-2214

12. Delmée M, Avesani V, Ernest I, Surleraux M. Detection of
We regard the work described here as a preliminary step. Our choice of serogroup $\mathrm{G}$ as a proving system was guided by the early availability of a specific antiserum, rather than particular clinical interest. Although c. 25 serogroups, including the PAGE subgroups within serogroup A, are known, in our experience of serogrouping $>6000$ isolates, the eight most frequent serogroups cover about $80 \%$ of all isolates (unpublished data). Moreover, the more clinically significant serogroups are restricted to six: $\mathrm{C}, \mathrm{G}$, $\mathrm{H}, \mathrm{K}, \mathrm{A} 1$ and $\mathrm{A} 8$. The problems of the multiplicity of reagents required for a workable rather than a comprehensive PACIA are not as formidable as might appear at first sight. The fact that some serogroups encompass toxigenic and non-toxigenic strains might be overcome by testing in PACIA and with rapid, direct toxin detection kits. Such a system would offer a combination of rapid detection of the organism and the toxins, and typing information that would be valuable in diagnosis, treatment and cross-infection control. specific antigens for ten serogroups of Clostridium difficile. Mol Cell Probes 1990; 4: 1-10.

13. Masson PL, Cambiaso CL, Collet-Cassart D, Magnusson CGM, Richards CB, Sindic CJM. Particle counting immunoassay (PACIA). Methods Enzymol 1981; 74 (part C): $106-139$.

14. George WL, Sutter VL, Citron D, Finegold SM. Selective and differential medium for isolation of Clostridium difficile. $J$ Clin Microbiol 1979; 9: 214-219.

15. Galanti LM, Cambiaso CL, Cornu CJ, Lamy ME, Masson PL. Immunoassay of hepatitis B surface antigen by particle counting after pepsin digestion. $J$ Virol Methods $1987 ; 18$ : 215-224.

16. Kamiya S, Nakamura S, Yamakawa K, Nishida S. Evaluation of a commercially available latex immunoagglutination test kit for detection of Clostridium difficile D-1 toxin. Microbiol Immunol 1986; 30: 177-181.

17. Kelly MT, Champagne SG, Sherlock $\mathrm{CH}$, Noble MA, Freeman HJ, Smith JA. Commercial latex agglutination test for detection of Clostridium difficile-associated diarrhea. J Clin Microbiol 1987; 25: 1244-1247.

18. Lyerly DM, Wilkins TD. Commercial latex test for Clostridium difficile toxin A does not detect toxin A. J Clin Microbiol 1986; 23: 622-623.

19. Borriello SP, Barclay FE, Reed PJ, Welch AR, Brown JD, Burdon DW. Analysis of latex agglutination test for Clostridium difficile toxin A (D-1) and differentiation between $C$. difficile toxins $\mathrm{A}$ and $\mathrm{B}$ and latex reactive protein. J Clin Pathol 1987; 40: 573-580.

20. Delmée M, Mackey T, Hamitou A. Evaluation of a new commercial Clostridium difficile toxin A enzyme immunoassay using diarrhoeal stools. Eur J Clin Microbiol Infect Dis 1992; 11 : 246-249.

21. Shanholtzer CJ, Willard KE, Holter JJ, Olson MM, Gerding DN, Peterson LR. Comparison of the VIDAS Clostridium difficile toxin $\mathrm{A}$ immunoassay with $C$. difficile culture and cytotoxin and latex tests. J Clin Microbiol 1992; 30: $1837-1840$.

22. Barbut F, Kajzer C, Planas N, Petit J-C. Comparison of three enzyme immunoassays, a cytotoxicity assay, and toxigenic culture for diagnosis of Clostridium difficile-associated diarrhea. J Clin Microbiol 1993; 31 : 963-967.

23. Limet JN, Moussebois CH, Cambiaso CL, Vaerman JP, Masson PL. Particle counting immunoassay. IV. The use of $\mathrm{F}\left(\mathrm{ab}^{\prime}\right)_{2}$ fragments and N-chloracetyl lysine N-carboxy- 
anhydride for their coupling to polystyrene latex particles. J Immunol Methods 1979; 28: 25-32.

24. Borriello SP, Honour P. Concomitance of cytotoxigenic and non-cytotoxigenic Clostridium difficile in stool specimens. $J$ Clin Microbiol 1983; 18: 1006-1007.

25. Delmée M, Avesani V. Virulence of ten serogroups of Clostridium difficile in hamsters. $J$ Med Microbiol 1990; 33: 85-90.
26. Borriello SP, Barclay FE. Protection of hamsters against Clostridium difficile ileocaecitis by prior colonisation with non-pathogenic strains. J Med Microbiol 1985; 19: 339-350.

27. Seal D, Borriello SP, Barclay F, Welch A, Piper M, Bonnycastle M. Treatment of relapsing Clostridium difficile diarrhoea by administration of a non-toxigenic strain. Eur J Clin Microbiol 1987; 6: 51-53. 